\title{
The possible role of NS3 protease activity of hepatitis C virus on fibrogenesis and miR-122 expression in hepatic stellate cells
}

\author{
S. KHANIZADEH ${ }^{1,2}$, M. RAVANSHAD ${ }^{1 *}$, S. Y. HOSSEINI ${ }^{3}$, P. DAVOODIAN ${ }^{4}$, A. N. ZADEH ${ }^{5}$, F. SABAHI ${ }^{1}$, \\ J. SARVARI ${ }^{3}$, Z. KHANLARI ${ }^{1}$, M. HASANI-AZAD ${ }^{4}$
}

\begin{abstract}
${ }^{1}$ Department of Virology, Faculty of Medical Sciences, Tarbiat Modares University, Tehran, Iran; ${ }^{2}$ Hepatitis Research Center, Lorestan University of Medical Sciences, Khorramabad, Iran; ${ }^{3}$ Department of Bacteriology and Virology, Shiraz University of Medical Sciences, Shiraz, Iran; ${ }^{4}$ Infectious and Tropical Diseases Research Center, Hormozgan University of Medical Sciences, Bandar Abbas, Iran; ${ }^{5}$ Molecular Medicine Research Center, Hormozgan University of Medical Sciences, Bandar Abbas, Iran
\end{abstract}

Received October 22, 2015; revised December 18, 2015; accepted June 22, 2016

\begin{abstract}
Summary. - The various roles of hepatitis C virus (HCV) NS3 protein in viral pathogenesis are emphasized, especially in the progression of fibrosis and tumors. The levels of miR-122 have been widely accepted as a critical factor in viral pathogenesis and disease progression. However, the possible correlation between miR-122 levels and fibrosis state has been less investigated. Therefore, in this study, plasmids expressing protease competent and protease mutated non-structural proteins 3 (NS3) were transfected into LX-2 cell line. Subsequently, the total RNA was extracted and real-time PCR was performed to measure the expression level of miR-122, collagen type 1 alpha 1 (COL1A1), alpha smooth muscle actin ( $\alpha$-SMA), and tissue inhibitor of metaloproteinase 1 (TIMP-1). Moreover, the transforming growth factor beta (TGF- $\beta$ ) levels in the supernatants of transfected cells were evaluated by ELISA. The gene expression analysis of fibrotic genes and TGF- $\beta$ cytokine in LX- 2 cells showed that protease competent NS3 had a significant fibrogenic impact when compared to protease defective NS3 or GFP control plasmids ( $\mathrm{P}<0.001)$. The results also demonstrated that the expression of miR-122 was downregulated in both versions of the cells transfected with NS3 plasmids $(\mathrm{P}<0.01)$ irrespective of protease function. These results suggested that the protease function of NS3 protein is a crucial factor for the induction of hepatic fibrosis but it doesn't play a complete role in the expression of miR-122.
\end{abstract}

Keywords: HCV; miRNA; fibrosis; HSCs; NS3; protease; miR-122

\section{Introduction}

Hepatitis $\mathrm{C}$ virus (HCV) infection is one of the most common causes of chronic liver diseases in the world. An estimated 170 million infected patients worldwide are at high risk for advanced liver diseases, such as liver fibrosis,

*Corresponding author. E-mail: ravanshad@modares.ac.ir; phone: +98-2182883836.

Abbreviations: $\mathrm{COL1A} 1=$ collagen type 1 alpha $1 ; \mathrm{HCC}=$ hepatocellular carcinoma; HCV = hepatitis C virus; HSCs = hepatic stellate cells; NS3 = non-structural protein $3 ; \alpha-S M A=$ alpha smooth muscle actin; TGF- $\beta$ = transforming growth factor beta; TIMP-1 = tissue inhibitor of metaloproteinase 1 cirrhosis, and hepatocellular carcinoma (HCC) (Sy and Jamal, 2006).

Although, molecular mechanisms of liver fibrosis, a relevant consequence of $\mathrm{HCV}$ infection, are discussed frequently/continuously, the issue remains as controversial and elusive as ever. Alteration of gene expression in HCV infected liver cells is supposed to play a profound role in the progression of liver fibrosis, and specific viral proteins are frequently identified to be responsible for this transformation. Modulation of gene expression by HCV NS3 protein is involved in liver disease and counts as a key mediator of disease progression toward persistent disease and clinical outcomes such as liver fibrosis, cirrhosis and HCC (Bataller et al., 2004; Selimovic et al., 2012; Wu et al., 2011; Nguyen et al., 2003). While hepatocytes are the main site of viral repli- 
cation, some controversial reports have claimed that $\mathrm{HCV}$ virus can infect hepatic stellate cells (HSCs) and modulate fibrosis signaling pathways and cell activation/transformation (Selimovic et al., 2012; Wu et al., 2011).

Non-structural protein 3 , a bi-functional protein with protease and helicase activity is proposed to play significant role in hepatic fibrosis initiation/progression (Sakata et al., 2013). Different molecular pathways are speculated to be involved in the role that NS3 plays in liver fibrosis. Endogenous expression of NS3 protein inside HSCs is indicated to be fibrotic at comparable levels with core protein (Selimovic et al., 2012). Recent achievements have also suggested that the NS3 protein enhances liver fibrosis through protease activity and via direct binding to TGF- $\beta$ receptors (Sakata et al., 2013). However, more research is needed to determine the exact role of NS3 protease activity in the initiation and progression of fibrosis.

Numerous studies have shown that microRNAs are responsible for controlling cellular processes and their dysregulation has also been associated with a wide range of disorders, such as tissue fibrosis and cancer (Gurtan and Sharp, 2013; Wanga et al., 2011; Noetel et al., 2012). Furthermore, HCV proteins could modulate the expression of host cell microRNAs and fibrotic genes during liver fibrosis. Deregulated microRNA expression has been shown to influence the replication of HCV in liver cells. As a wellcharacterized phenomenon, higher expression of miR-122, a liver-specific microRNA, plays a boosting role in the replication of HCV (Jiang et al., 2010; Pfeffer and Baumert, 2014; Li et al., 2012). Recently published findings have indicated the possible involvement of miR-122 expression in fibrosis development. These findings have suggested that miR-122 may negatively regulate collagen production in HSCs and therefore the dysregulation of miR-122 might exacerbate the fibrosis state in vitro (Li et al., 2013). However, the exact role of HCV proteins, the effects of NS3 expression on the level of miR-122 during HSC fibrosis, and the role of its protease activity in these processes needs to be further clarified.

Here, our aims were to investigate the effects of protease function of NS3 protein on HSC fibrogenesis and also on the coincidental expression levels of miR-122 in LX-2 cells.

\section{Materials and Methods}

Cells and plasmid transfection. The plasmids expressing NS3 protein with functional and mutated protease domain were constructed in another study (Khanlari et al., 2014). They were designated as pNS3 and pTNS3, respectively, while the control plasmid expressing GFP protein was designated as pGFP. The pTNS3 construct harbored a critical mutation making NS3 unable to perform protease activity as confirmed before (Khanlari et al., 2014). The LX-2 cells (an immortalized human stellate cell line), were kindly provided by Professor Scott Friedman (Mount Sinai School of Medicine,
New York, USA). The LX-2 cells show the typical features of partly active stellate cells, hence can be used as a sustained model for human HSC studies (Xu et al., 2005). The cells were grown in Dulbecco's modified Eagle's medium (DMEM, Gibco, USA) supplemented with $5 \%$ bovine fetal serum (FBS, Sigma, USA), $100 \mathrm{U} / \mathrm{ml}$ penicillin-streptomycin (Gibco), and $2 \mathrm{mmol} / \mathrm{l} \mathrm{L}$-glutamine, and were incubated at $37^{\circ} \mathrm{C}$ in a $5 \% \mathrm{CO}_{2}$ humidified air atmosphere. On the day prior to the transfection, the LX- 2 cells were seeded on $6-\mathrm{cm}^{2}$ tissue culture plates at a density of $4 \times 10^{5}$ cells per well and left to grow overnight. Cells were transfected with pNS3 and pTNS3 using the Lipofectamine 2000TM reagent in an incomplete DMEM medium, according to the manufacturer's instructions, while the pGFP plasmid was used as the control. The medium was then replaced with a fresh complete DMEM medium followed by another $18 \mathrm{hr}$ of incubation. Besides, to prepare fully fibrotic LX-2 cells, a mixture of TGF- $\beta 1$ and leptin hormone was applied coincidentally. To prepare home-made TGF- $\beta 1$, LX-2 cells were seeded into a $75 \mathrm{~cm}^{2}$ flask in a serum free medium and were supplemented with $75 \mathrm{ng} / \mathrm{ml}$ leptin (Cao et al., 2004) as a profibrogenic hormone (Sigma). After $48 \mathrm{hr}$ of incubation, the supernatant containing TGF- $\beta 1$ was concentrated by Amicon` Ultra centrifugal filters for protein concentration ( $5 \mathrm{~K}$ size) and then it was measured using the ELISA method. The produced TGF- $\beta 1$ was kept at $-80^{\circ} \mathrm{C}$ until use. The mixture of home-made TGF- $\beta(1-5 \mathrm{ng} / \mathrm{ml})$ and leptin (50 $\mathrm{ng} / \mathrm{ml}$ ) in serum free media were applied to the culture media to induce LX-2 activation as the positive control.

RNA extraction and reverse transcription. Total RNA was extracted using the Trizol reagent (Invitrogen, USA) according to the manufacturer's instructions and then $1 \mu \mathrm{g}$ of extracted RNA was reverse transcribed into cDNA using the Revert aid first strand cDNA

Table 1. The PCR primers used in this study

\begin{tabular}{|c|c|c|}
\hline Size & Primer pair & Gene name \\
\hline \multirow[t]{2}{*}{226} & $\begin{array}{l}\text { 5'-GAA GGT GAA GGT CGG AGT C-3' } \\
\text { (sense) }\end{array}$ & GAPDH \\
\hline & $\begin{array}{l}\text { 5'-GAA GAT GGT GAT GGG ATT TC-3' } \\
\text { (antisense) }\end{array}$ & \\
\hline \multirow[t]{2}{*}{202} & $\begin{array}{l}\text { 5'-TAC TTC CAC AGG TCC CAC AAC-3' } \\
\text { (sense) }\end{array}$ & TIMP1 \\
\hline & $\begin{array}{l}\text { 5'-GTT TGC AGG GGA TGG ATA AAC-3' } \\
\text { (antisense) }\end{array}$ & \\
\hline \multirow[t]{2}{*}{147} & $\begin{array}{l}\text { 5'-GACAATGGCTCTGGGCTCTG -3' } \\
\text { (sense) }\end{array}$ & a-SMA \\
\hline & $\begin{array}{l}\text { 5'-CTGTGCTTCGTCACCCACG -3' } \\
\text { (antisense) }\end{array}$ & \\
\hline \multirow[t]{2}{*}{140} & $\begin{array}{l}\text { 5'-GAG GGC CAA GAC GAA GAC ATC-3' } \\
\text { (sense) }\end{array}$ & COL1A1 \\
\hline & $\begin{array}{l}\text { 5'-CAG ATC ACG TCA TCG CAC AAC-3' } \\
\text { (antisense) }\end{array}$ & \\
\hline \multirow[t]{2}{*}{95} & $\begin{array}{l}\text { 5'-CTCGCTTCGGCAGCACATATACT-3' } \\
\text { (sense) }\end{array}$ & U6 \\
\hline & $\begin{array}{l}\text { 5'-ACGCTTCACGAATTTGCGTGTC-3' } \\
\text { (antisense) }\end{array}$ & \\
\hline
\end{tabular}


synthesis kit (Thermo Fisher Scientific, USA). The miRNA-122 was reverse transcribed into cDNA using miRNA $1^{\text {st }}$-Strand cDNA synthesis kit (Stratagene, USA), then qRT-PCR was carried out using the high specificity miRNA QPCR core reagent kit (Agilent Technologies, USA) according to the manufacturer's protocol.

Real-time PCR. The primer pairs for a-SMA, TIMP1, COL1A1, and also GAPDH (internal control) were designed by NCBI PrimerBLAST online software and listed in Table 1 . The selected forward primer for miR-122 was: 5'-GGAGTGTGACAATGGTGTTTG-3' and the universal reverse primer as the reverse primer was obtained from the cDNA synthesis kit. Besides, as the normalization step, the expression level of U6 snRNA was used as the internal control compared with miR-122 expression. The human GAPDH and U6 snRNA were employed as reference genes for the normalization of reactions, while $\mathrm{H}_{2} \mathrm{O}$ was used as the negative control of reactions and RNA extracts were used as the negative control of cDNA synthesis enrolled in all PCR runs. The mRNA levels were quantified using SYBR green I master mix (Bioneer, S. Korea) by Applied Biosystems StepOne ${ }^{\mathrm{Tx}}$ Instrument system. The reaction mixtures were prepared according to the recommended protocol and the amplification reactions were performed in 40 cycles of 15 sec at $94^{\circ} \mathrm{C}$ for denaturation and $25 \mathrm{sec}$ at $60^{\circ} \mathrm{C}$ for the annealing
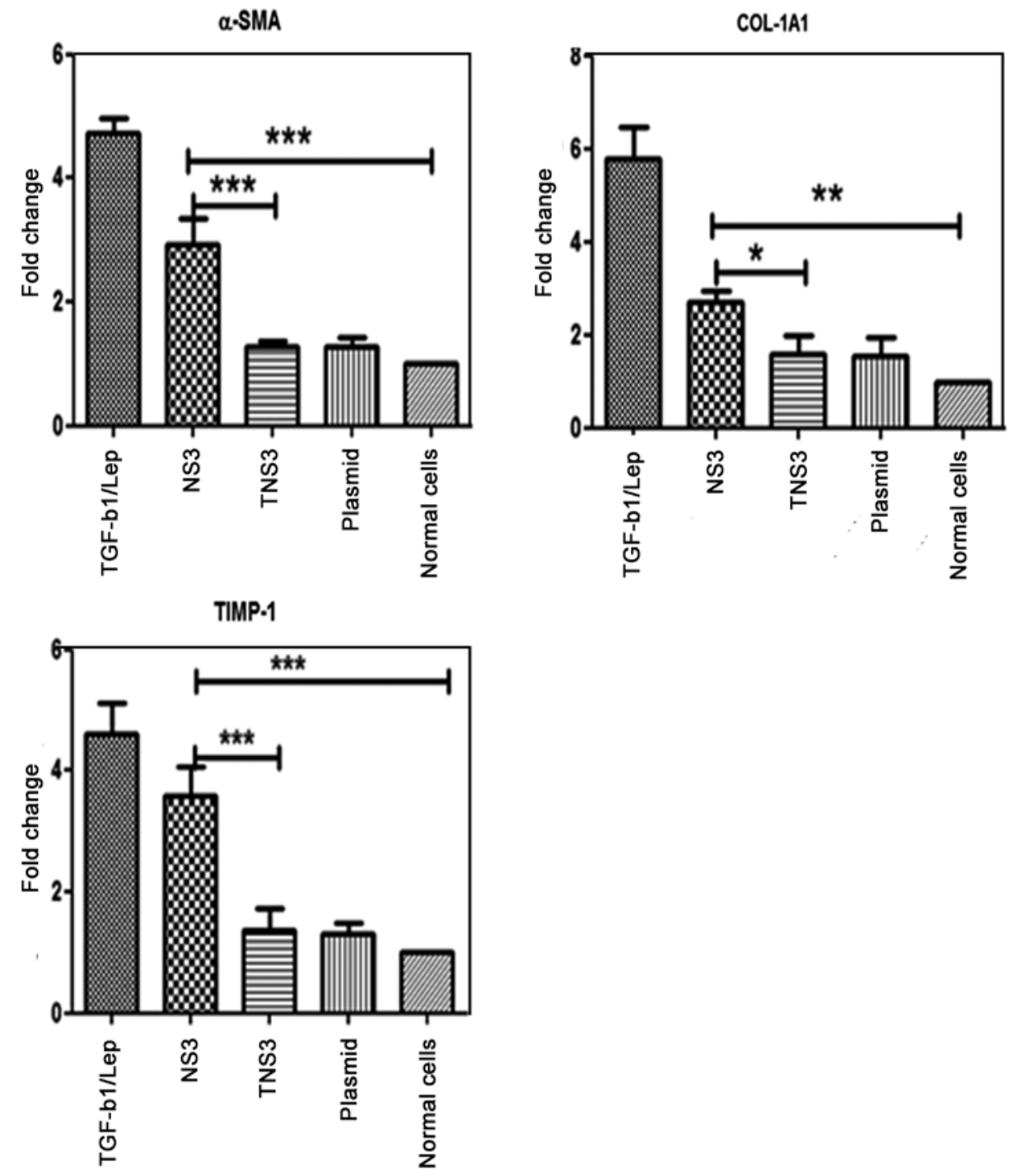

Fig. 1

The effects of protease competent HCV (NS3) and protease defective HCV (TNS3) on collagen (a), a-SMA (b) and TIMP-1 (c) gene expression was evaluated by real-time PCR

Each bar is representative of the mean for at least 3 experiments and presents the fold increase/decrease compared to the expression of normal cells. ${ }^{*} \mathrm{P}<0.05,{ }^{* *} \mathrm{P}<0.01$ and ${ }^{* * *} \mathrm{P}<0.001$ indicate the significant fold changes of test groups with empty GFP plasmid and normal LX-2 cells. 
and extension steps. The amplification signals for different samples were normalized to the relevant GAPDH and U6 snRNA Ct (cycle threshold), then the delta-delta CT (2- $\Delta \Delta \mathrm{CT})$ method was applied to compare mRNA levels of tests versus control (normal cells) and they were finally represented as the fold change in data analysis.

ELISA assay for TGF- $\beta 1$ measurement. Nearly $24 \mathrm{hr}$ after LX-2 transfection by different plasmids, the released bioactive TGF- $\beta 1$ in the supernatant was quantified by the help of the human-mouse TGF- $\beta$ ELISA kit (eBioscience, USA) according to the manufacturer's instructions. All the samples were first acid-activated and the residual TGF- $\beta 1$ level (due to the possible presence of home-made TGF- $\beta$ or calf serum) was subtracted from the final calculation. The absorbance was measured at A 450 by the ELISA reader (BioTek Elx 808 , USA) and then the data were calculated against the standard curve and adjusted to $\mathrm{pg} / \mathrm{ml}$ of the culture medium.

Statistical analysis. All data that are presented in the results section belonged to at least three independent experiments. Statistical analyses were performed using the Graph Pad Prism software. They were analyzed using one-way ANOVA to evaluate the difference between mediums. The statistical significance between the controls and the treated groups was further evaluated by the Tukey post-test. The statistical significance level was set at $\mathrm{P} \leq 0.05$.

\section{Results}

The protease competent NS3 protein induced a noticeable fibrotic effect

The mRNA expression levels for pro-fibrotic genes including $\alpha$-SMA (Fig. 1a), COL1A1 (Fig. 1b) and TIMP-1 (Fig. 1c), were evaluated after the transfection of HSCs with protease competent and protease mutated NS3. As shown in Fig. 1, protease competent NS3 showed significant induction of fibrotic genes compared with normal cells $(\mathrm{P}<0.001)$. On the other hand, mutated NS3 (TNS3) and GFP protein (as the control plasmid) exhibited a similar pattern of induction for fibrotic genes in comparison with the normal cell group. This finding emphasized that the protease domain of NS3 is the major part of the protein contributing to fibrosis through up-regulation of corresponding genes.

miR-122 downregulation is NS3 protease function independent

The expression level of miR-122 in test groups revealed an opposite trend in comparison with the expression of fibrotic genes. While the protease competent NS3 protein exhibited more significant decrement in miR-122 level when compared to normal cells $(\mathrm{P}<0.001)$, protease mutated NS3 exhibited a measurable reduction as well. This qPCR data showed that the expression of miR-122 in both versions of NS3 expressing cells compared with the GFP plasmid receiving group was

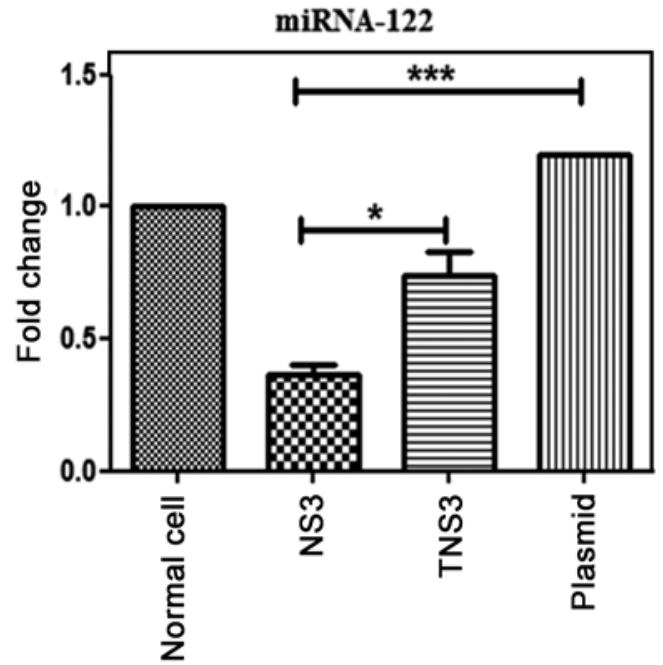

Fig. 2

The effects of protease competent NS3 and protease defective TNS3 on the expression of miR-122 in treated LX2

Each bar is representative of the mean \pm standard deviation from at least three measurements and the final results enrolled. ${ }^{\star} \mathrm{P}<0.05$ and ${ }^{\star * *} \mathrm{P}<0.001$ show significant levels compared to the normal cell (untreated-LX2 cell).

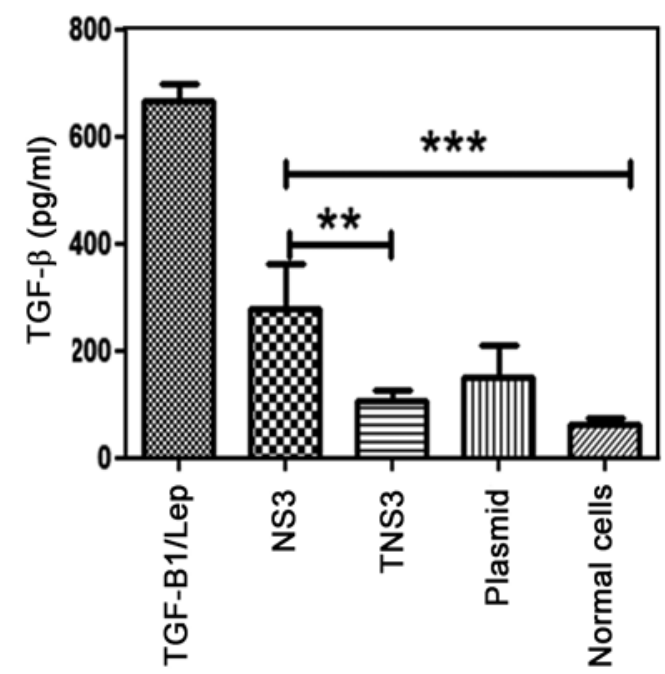

Fig. 3

The impact of protease competent NS3 and protease defective TNS3 on TGF- $\beta$ production from $\mathrm{LX}-2$ cells

Each bar is representative of the mean \pm SD from at least three measurements and the final results enrolled after subtraction of background TGF- $\beta$ (exogenous sources). ${ }^{* *} \mathrm{P}<0.01$ and ${ }^{* * *} \mathrm{P}<0.001$ show significant levels compared to the positive control group (TGF- $\beta 1$-treated cells).

significantly decreased $(\mathrm{P}<0.05)$ (Fig. 2 ). The finding may support the less impressive role of protease domain of NS3 in decreasing miR-122 during fibrosis events, albeit the protease 
competent form of the protein showed a significant decrease even when compared with the TNS3 form $(\mathrm{P}<0.01)$.

The protease competent version of NS3 protein upregulated TGF- $\beta 1$ production

As a major player element in the fibrosis process, TGF- $\beta 1$ cytokine level was evaluated to monitor the state of fibrogenesis in LX- 2 cells. The ELISA result of bioactive TGF- $\beta 1$ measurement indicated similar findings with qPCR results of fibrotic genes. These results showed that the protease competent version of the NS3 protein can elevate TGF- $\beta 1$ production from LX-2 cells when compared to normal cells $(\mathrm{P}<0.001)$ and the protease deficient NS3 $(\mathrm{P}<0.01)$ (Fig. 3). The data also indicated no significant difference $(\mathrm{P}>0.05)$ between GFP plasmid and protease defective NS3 plasmids in TGF- $\beta 1$ production that emphasized the critical role of the protease part of the protein for this upregulation.

\section{Discussion}

Liver fibrosis, as an extra deposition of the ECM process, arises after chronic hepatitis $\mathrm{C}$ infection without treatment. HSCs are considered as the major players in the establishment and development of liver fibrosis. During the development of liver fibrosis, quiescent HSCs can be activated by hepatitis $\mathrm{C}$ and $\mathrm{B}$ viruses and can transform into a myofibroblast-like phenotype (Bataller et al., 2004; Schuppan et al., 2003). The molecular basis of HCV-related hepatic fibrosis is not obviously clarified yet and the direct role of corresponding viral proteins in these events is also under investigation (Schuppan et al., 2003; Gutierrez-Reyes et al., 2007). From limited studies, the HCV proteins including NS3, core and NS5 proteins have been ambiguously supposed to be the direct acting factors involved in the fibrosis process. It has been demonstrated that the HCV core protein can directly interact with HSCs via TLR2 and also through involving the obese receptors which results in the upregulation of the profibrogenic genes (Bataller et al., 2004; Wu et al., 2013).

In our work, the aim was to assess the effect of the protease function of the NS3 protein on the fibrosis induction of HSCs for the first time. Herein, we observed that the interaction of the protease competent version of the NS3 protein with HSC cells leads to increased expression of $\alpha$-SMA, Col-I or COL1A1, TIMP-1 genes and TGF- $\beta$ cytokine. Our results revealed that NS3 with protease function is significantly effective in inducing fibrogenic state in HSCs as compared to control cells, while the protease mutated form of NS3 has significantly less fibrotic effect on HSCs. All the expression assays demonstrated that the protease function of NS3 is the main prerequisite for fibrosis development. These data were in agreement with the pioneer study that was performed by Bataller (Bataller et al., 2004). They evaluated the effect of NS3 on HSCs by using adenoviruses expressing the NS3NS5 proteins and concluded that bioactive TGF- $\beta 1$ and other profibrotic genes upregulated following NS3 protein expression. Recently, another study also showed similar data and demonstrated that HCV NS3 protease function increases hepatic fibrosis by activating TGF- $\beta 1$ type I receptors in HSCs (Sakata et al., 2013) and emphasized the role of the protease part of NS3 in liver fibrosis via mimicking the growth factor.

Recently, dozens of experiments have been performed, investigating the role of microRNAs on liver fibrosis during hepatitis virus infection (Li et al., 2012; Vettori et al., 2012). It was noticed that miRNAs regulate the signaling of inflammatory cytokines and the IFN pathway in HSCs during liver fibrosis (Vettori et al., 2012). It has been shown that HCV infection leads to the modulation of the expression of microRNAs by affecting the main cellular signaling pathways. In spite of some reports about the role of the $\mathrm{HCV}$ core protein in the fibrogenesis of HSCs and also the modulation of microRNAs, the impact of the HCV NS3 protein on HSCs has been described poorly (Jiang et al., 2010; Shrivastava et al., 2013).

The role of miR-122, as the most abundant microRNA in the hepatocytes had been highlighted in HCV infection, so that its regulation has been applied as a new therapeutic strategy for virus eradication (Pfeffer and Baumert, 2014; $\mathrm{Li}, 2013)$. It was demonstrated that miR-122 promotes $\mathrm{HCV}$ replication via post-transcriptional suppression of the heme oxygenase enzyme and other mechanisms (Pfeffer and Baumert, 2014).

There is, however, only limited information about the state of miR-122 expression during the fibrotic stage of an HSC and following HCV protein expression. It is not clearly demonstrated 1) if miR-122 can directly modulate fibrosis and 2) what would happen after its expression in the fibrotic state, 3) what is the NS3 protein impact on miR-122 level during expression in HSC and 4) what is the role of the protease part of NS3 in this possible impact? In our study, the expression level of miR-122 was measured intracellularly, following the transfection of HSCs with complete and mutated forms of NS3. The gene expression analysis of miR-122 in LX-2 cells showed that both versions of NS3 proteins can lead to the downregulation of miR-122 expression in HSCs when compared to normal cells or GFP control plasmids $(\mathrm{P}<0.05)$. Previous studies have shown that miRNA-122 expression could be decreased in Huh7.5.1 cells transfected with HCV core protein, which corresponds with our results emphasizing the possible role of miR-122 in fibrogenesis and liver cirrhosis (Li et al., 2013; Ezzat et al., 2014). Furthermore, other studies in mouse HSCs have shown that the overexpression of miRNA-122 reduced the collagen level, and lower ECM 
deposition is an indicator of less liver fibrosis related diseases (Jopling, 2008; Li, 2013; Bandiera et al., 2015). Furthermore, our achievements also indicated that, while both versions of NS3 proteins downregulated miR-122, a measurable difference between protease competent and protease mutated forms was observed as is indicated by the more but not fully dependent role of protease in this function $(\mathrm{P}>0.01)$.

In conclusion, the results of our study indicated that protease competent HCV NS3 protein, unlike NS3 without protease function, can induce fibrogenic state in human HSCs. Hence, while both versions of NS3 lead to decreased expression of miR-122 in HSCs following cell transfection, the competent form of NS3 had a more suppressive role on miR-122. Therefore, we can conclude that possibly 1 ) miR-122 can directly modulate fibrosis, 2) its expression is significantly suppressed in fibrotic state, 3) NS3 protein impacts on miR-122 level in HSC and 4) the protease part of NS3 exhibits some but not total possible impact on miR-122 expression. The exploration of the interaction between $\mathrm{HCV}$ proteins and HSCs may facilitate our understanding of the causes of chronic liver diseases and provide new opportunities for the treatment and management of disease. However, further studies are required to find out the precise basis by which $\mathrm{HCV}$ protein functions.

Acknowledgement. This work was supported by grants from Tarbiat Modares University as part of a PhD thesis and Infectious \& Tropical Diseases Research Center of the Hormozgan University of Medical Sciences.

\section{References}

Bandiera S, Pfeffer S, Baumert TF, Zeisel MB (2015): miR-122 - A key factor and therapeutic target in liver diseases. J. Hepatol. 62, 448-457. http://dx.doi.org/10.1016/j.jhep.2014.10.004

Bataller R, Paik YH, Lindquist JN, Lemasters JJ, Brenner DA (2004): Hepatitis $C$ virus core and nonstructural proteins induce fibrogenic effects in hepatic stellate cells. Gastroenterology 126, 529-540. http://dx.doi.org/10.1053/j. gastro.2003.11.018

Cao Q, Mak KM, Ren C, Lieber CS (2004): Leptin stimulates tissue inhibitor of metalloproteinase-1 in human hepatic stellate cells. Respective roles of the jak/stat and jak-mediated H2O2-dependent MAPK pathways. J. Biol. Chem. 279, 4292-4304. http://dx.doi.org/10.1074/jbc.M308351200

Ezzat H, Lotfy AM, Alalfy MN, El-Taher SM, Mokhtar A, Mohamed SA, EL-Senosy FM (2014): The Significance of circulating micro RNA-122 as a non invasive diagnostic marker of liver injury in egyptian chronic hepatitis $\mathrm{C}$ virus infected and cirrhotic patients with and without hepatocellular carcinoma. Clin. Med. Diag. 4, 1-8.

Jiang X, Tsitsiou E, Herrick SE, Lindsay MA (2010): MicroRNAs and the regulation of fibrosis. FEBS J. 277, 2015-2021. http:// dx.doi.org/10.1111/j.1742-4658.2010.07632.x
Jopling CL (2008): Regulation of hepatitis C virus by microRNA122. Biochem. Soc. Trans. 36, 1220-1223. http://dx.doi. org/10.1042/BST0361220

Khanlari Z, Sabahi F, Hosseini SY, Ghaderi M (2014): HCV NS3 blocking effect on IFN induced ISGs like Viperin and IL28 with and without NS4A. Hepat. Mon. 14, e17822. http:// dx.doi.org/10.5812/hepatmon. 17822

Li J (2013): miR-122 regulates collagen production via targeting hepatic stellate cells and suppressing P4HA1 expression. J. Hepatol. 58, 522-528. http://dx.doi.org/10.1016/j. jhep.2012.11.011

Li S, Zhu J, Fu H, Wan J, Hu Z, Liu S, Li J, Tie Y, Xing R, Zhu J, Sun Z, Zheng X (2012): Hepato-specific microRNA-122 facilitates accumulation of newly synthesized miRNA through regulating PRKRA. Nucleic Acids Res. 40, 884-891. http:// dx.doi.org/10.1093/nar/gkr715

Li S, Xing X, Yang Q, Xu H, He J, Chen Z, Zhu H (2013): The effects of hepatitis $\mathrm{C}$ virus core protein on the expression of miR-122 in vitro. Virology J. 10, 98. http://dx.doi. org/10.1186/1743-422X-10-98

Gurtan AM, Sharp PA (2013): The role of miRNAs in regulating gene expression networks. J. Mol. Biol. 425, 3582-3600. http://dx.doi.org/10.1016/j.jmb.2013.03.007

Gutierrez-Reyes G, Gutierrez-Ruiz MC, Kershenobich D (2007): Liver fibrosis and chronic viral hepatitis. Arch. Med. Res. 38,644-651. http://dx.doi.org/10.1016/j. arcmed.2006.10.001

Nguyen H, Mudryj M, Guadalupe M, Dandekar S (2003): Hepatitis $\mathrm{C}$ virus core protein expression leads to biphasic regulation of the p21 cdk inhibitor and modulation of hepatocyte cell cycle. Virology 312, 245-53. http://dx.doi. org/10.1016/S0042-6822(03)00209-5

Noetel A, Kwiecinski M, Elfimova N, Huang J, Odenthal M (2012): microRNA are central players in anti- and profibrotic gene regulation during liver fibrosis. Front. Physiol. 3, 49. http://dx.doi.org/10.3389/fphys.2012.00049

Pfeffer S, Baumert TF (2014): Impact of microRNAs for pathogenesis and treatment of hepatitis $\mathrm{C}$ virus infection. Clin. Res. Hepat. Gastroent. 38, 318-330.

Sakata K, Hara M, Terada T, Watanabe N, Takaya D, Yaguchi SI, Matsumoto T, Matsuura T, Shirouzu M, Yokoyama S, Yamaguchi T, Miyazawa K, Aizaki H, Suzuki T, Wakita T, Imoto M, Kojimaa S (2013): HCV NS3 protease enhances liver fibrosis via binding to and activating TGF- $\beta$ type I receptor. Scientific Reports 3, 32-43. http://dx.doi. org/10.1038/srep03243

Schuppan D, Krebs A, Bauer M, Hahn EG (2003): Hepatitis C and liver fibrosis. Cell Death Differ. 10 (Suppl. 1), S59-S67. http://dx.doi.org/10.1038/sj.cdd.4401163

Selimovic D, El-Khattouti A, Ghozlan H, Haikel Y, Abdelkader O, Hassan M (2012): Hepatitis C virus-related hepatocellular carcinoma: An insight into molecular mechanisms and therapeutic strategies. World J. Hepatol. 4, 342-355.

Shrivastava S, Mukherjee A, Ray RB (2013): Hepatitis C virus infection, microRNA and liver disease progression. World J. Hepatol. 5,479-486. http://dx.doi.org/10.4254/ wjh.v5.i9.479 
Sy T, Jamal M (2006): Epidemiology of hepatitis C virus (HCV) infection. International J. Med. Sci. 3, 41-46. http://dx.doi. org/10.7150/ijms.3.41

Vettori S, Gay S, Distler O (2012): Role of MicroRNAs in Fibrosis. Open Rheumatol. J. 6,130-139. http://dx.doi. org/10.2174/1874312901206010130

Wanga Y, Lib XI, Hu H (2011): Transcriptional regulation of coexpressed microRNA target genes. Genomics 98,445-452. http://dx.doi.org/10.1016/j.ygeno.2011.09.004

Wu C, Gilroy R, Taylor R, Olyaee M, Abdulkarim B, Forster J, O'Neil M, Damjanov I, Wan YJ (2011): Alteration of hepatic nuclear receptor-mediated signaling pathways in $\mathrm{HCV}$ patients with and without a history of alcohol drinking. Hepatology 54,1966-1974. http://dx.doi.org/10.1002/ hep. 24645

Wu CF, Lin YL, Huang YT (2013): Hepatitis C virus core protein stimulates fibrogenesis in hepatic stellate cells involving the obese receptor. J. Cell. Biochem. 114, 541-550. http:// dx.doi.org/10.1002/jcb.24392

Xu L, Hui AY, Albanis E, Arthur MJ, O'Byrne SM, Blaner WS, Mukherjee P, Friedman SL, Eng FJ (2005): Human hepatic stellate cell lines, LX-1 and LX-2: new tools for analysis of hepatic fibrosis. Gut 54, 142-151. http://dx.doi. org/10.1136/gut.2004.042127 